\title{
Facial-muscle weakness, speech disorders and dysphagia are common in patients with classic infantile Pompe disease treated with enzyme therapy
}

\author{
C. M. van Gelder • C. I. van Capelle • B. J. Ebbink • I. Moor-van Nugteren • \\ J. M. P. van den Hout • M. M. Hakkesteegt • P. A. van Doorn • I. F. M. de Coo • \\ A. J. J. Reuser • H. H. W. de Gier • A. T. van der Ploeg
}

Received: 10 July 2011 /Revised: 20 September 2011 /Accepted: 21 September 2011 /Published online: 19 October 2011

(C) The Author(s) 2011. This article is published with open access at Springerlink.com

\begin{abstract}
Classic infantile Pompe disease is an inherited generalized glycogen storage disorder caused by deficiency of lysosomal acid $\alpha$-glucosidase. If left untreated, patients die before one year of age. Although enzyme-replacement therapy (ERT) has significantly prolonged lifespan, it has
\end{abstract}

Communicated by: Ed Wraith

Competing interest: None declared.

Electronic supplementary material The online version of this article (doi:10.1007/s10545-011-9404-7) contains supplementary material, which is available to authorized users.

C. M. van Gelder • C. I. van Capelle • B. J. Ebbink •

A. T. van der Ploeg $(\square)$

Department of Pediatrics, Division of Metabolic Diseases and Genetics, Center for Lysosomal and Metabolic Diseases, Erasmus MC University Medical Center,

P.O. Box 2060, 3000 CB Rotterdam, the Netherlands

e-mail: a.vanderploeg@erasmusmc.nl

I. Moor-van Nugteren • M. M. Hakkesteegt • H. H. W. de Gier

Department of Otolaryngology,

Erasmus MC University Medical Center,

Rotterdam, the Netherlands

P. A. van Doorn · I. F. M. de Coo

Department of Neurology,

Erasmus MC University Medical Center,

Rotterdam, the Netherlands

\section{A. J. J. Reuser}

Department of Clinical Genetics, Center for Lysosomal and Metabolic Diseases, Erasmus MC University Medical Center, Rotterdam, the Netherlands

J. M. P. van den Hout

Departments of Pediatrics and Child Neurology, Division of Metabolic Diseases and Genetics, Center for Lysosomal and Metabolic Diseases, Erasmus MC University Medical Center, P.O. Box 2060, 3000 CB Rotterdam, the Netherlands also revealed new aspects of the disease. For up to 11 years, we investigated the frequency and consequences of facialmuscle weakness, speech disorders and dysphagia in longterm survivors. Sequential photographs were used to determine the timing and severity of facial-muscle weakness. Using standardized articulation tests and fibreoptic endoscopic evaluation of swallowing, we investigated speech and swallowing function in a subset of patients. This study included 11 patients with classic infantile Pompe disease. Median age at the start of ERT was 2.4 months (range 0.1-8.3 months), and median age at the end of the study was 4.3 years (range 7.7 months -12.2 years). All patients developed facial-muscle weakness before the age of 15 months. Speech was studied in four patients. Articulation was disordered, with hypernasal resonance and reduced speech intelligibility in all four. Swallowing function was studied in six patients, the most important findings being ineffective swallowing with residues of food $(5 / 6)$, penetration or aspiration (3/6), and reduced pharyngeal and/or laryngeal sensibility (2/6). We conclude that facial-muscle weakness, speech disorders and dysphagia are common in long-term survivors receiving ERT for classic infantile Pompe disease. To improve speech and reduce the risk for aspiration, early treatment by a speech therapist and regular swallowing assessments are recommended.

\section{Introduction}

Pompe disease (glycogen storage disease type II, acid maltase deficiency, OMIM \# 232300) is a rare autosomal recessive lysosomal storage disorder caused by mutations in the gene-encoding acid $\alpha$-glucosidase (EC 3.2.1.20) (Van der Ploeg and Reuser 2008; Hirschhorn and Reuser 2001). 
Severe mutations cause complete enzyme deficiency, resulting in the classic infantile form of Pompe disease, which was first described by Pompe in 1932 (Pompe 1932). Symptoms are caused by glycogen accumulation, mainly in skeletal, cardiac and smooth muscle, but also in other tissues, including the central and peripheral nervous system. In the first months of life, patients present with progressive muscle weakness, hypertrophic cardiomyopathy, respiratory problems and feeding difficulties. If untreated, this leads to death before the age of one year (Van den Hout et al. 2003; Kishnani et al. 2006a).

Although the lifespan of classic infantile Pompe patients has been significantly prolonged, and although motor functioning is improved by enzyme-replacement therapy (ERT), various extents of muscle weakness remain (Van den Hout et al. 2000, 2004; Kishnani et al. 2009; Nicolino et al. 2009; Muller et al. 2009; Kishnani et al. 2007; Kishnani et al. 2006b; Klinge et al. 2005a, b; Amalfitano et al. 2001; Chakrapani et al. 2010). This study focuses on weakness of the facial and bulbar muscles.

We simultaneously examined the prevalence and consequences of facial-muscle weakness, speech disorders and dysphagia in a cohort of patients with classic infantile Pompe disease who had been treated with ERT over a long period, in some cases up to 11 years.

\section{Patients and methods}

\section{Patients}

The study comprised 11 patients with classic infantile Pompe disease treated with ERT between 1999 and 2010 at Erasmus MC University Medical Center, Rotterdam, the Netherlands. Classic infantile Pompe disease was defined as 1.) symptoms of muscle weakness within six months of birth, 2.) hypertrophic cardiomyopathy, and 3.) severe GAA (the gene-encoding acid $\alpha$-glucosidase) mutations on both alleles. The diagnosis was confirmed by an enzyme-activity assay in leukocytes or fibroblasts. Patients were enrolled in clinical trials that investigated the safety and efficacy of ERT with recombinant human $\alpha$-glucosidase $(20 \mathrm{mg} / \mathrm{kg} /$ two weeks to $40 \mathrm{mg} / \mathrm{kg} /$ week). The Institutional Review Board approved the studies, and written informed consent was obtained from all parents.

Facial-muscle weakness

To examine the onset of facial-muscle weakness, we collected photographs of the face taken over a period of 24 months from the start of ERT. For this we used standardized photographs and videos taken every three months. The photographs were ordered arbitrarily and evaluated independently by three neurologists. The evaluators stated whether facial-muscle weakness was present, and, whether it was mild or severe. Facial-muscle weakness was defined as an expressionless face with an open drooping or tent-shaped mouth (Dubowitz 1978). To accept any judgement, the agreement of at least two evaluators was needed. If this was impossible, the evaluation was considered not to be applicable.

To further characterize facial-muscle weakness, the evaluators scored whether the following clinical features were present, absent or impossible to judge: ptosis, sunken cheeks, drooping of the lower lip, absence of the nasolabial folds, and absence of horizontal forehead lines. Ptosis was considered to be present when the upper eyelid was less than $2 \mathrm{~mm}$ from midpupil, or when asymmetry between the left and right upper eyelid was greater than $2 \mathrm{~mm}$. A recent photograph of each patient was collected to analyse progression over time.

Speech and swallowing function

Between 2008 and 2010, speech was assessed in patients older than 24 months or in those who spoke more than ten words $(n=4)$. Swallowing function was assessed in patients who were not fed by percutaneous endoscopic gastrostomy $(n=6)$. Assessments were repeated after at least one year.

Speech

First, a speech therapist conducted a thorough orofacial observation to detect whether speech was impaired by weakness or reduced movements of the lip and tongue. To evaluate speech, a modified form of the Dutch Schisis Articulation Examination was used, which examines spontaneous language, and the repetition of phonemes and words. The following items were examined: 1.) articulatory disorders (i.e. mispronunciation of speech sounds), 2.) hypernasal resonance (i.e. increased resonance by the nasal cavity), and 3.) speech intelligibility.

Additionally, a neuropsychologist tested for dysarthria using the Mayo Clinic Lists (Darley et al. 1969b), which also investigates respiration, phonation (i.e. the characteristics of voice production by the larynx), and prosody (i.e. speed and rhythm of speech).

\section{Swallowing function}

The speech therapist obtained a feeding history from all parents.

Pharyngeal swallowing function was assessed by an experienced otolaryngologist using fibreoptic endoscopic evaluation of swallowing (FEES) (Langmore et al. 1988). First, the masticatory pattern was investigated. Then, after the fibrescope had been introduced, the anatomy and function of the swallowing apparatus were examined: Velopharyngeal 
closure (i.e. sealing of the nasal cavity by the soft palate) was examined during speech, and the pharynx and larynx were screened for deviant anatomy, reduced pharyngeal squeeze, and impaired laryngeal function.

Next, pharyngeal swallowing function was examined while patients ingested food in a sitting position. Observation of swallowing function included premature spillage of food, delayed swallowing, nasal regurgitation, pharyngeal food residue, and penetration and aspiration of the food or pooling secretions. Penetration was defined as leakage of food into the laryngeal vestibule up to the level of the true vocal cords; aspiration was defined as leakage into the laryngeal vestibule below this level (Langmore 2001). Finally, we observed the sensory reaction of the pharynx and larynx.

\section{Associated clinical outcome measures}

At the time of speech and swallowing assessments, relevant clinical data on feeding (orally or tube feeding), airway infections, motor development, and hearing loss (Van Capelle et al. 2010) were collected.

\section{Results}

\section{Patients}

Eleven patients participated in this study. Table 1 summarizes each patient's clinical features. At the start of ERT all patients had symptoms of Pompe disease. All were hypotonic, and eight were fed by nasogastric tube.
Facial muscle weakness

In total, 96 photographs were collected of 11 patients. The median age at the first photo was 2.3 months (age range 0.1-8.8 months); the median age at the last was 49.2 months (age range 6.9 months-11.6 years).

Between the ages of 1.0 and 15.0 months (Table 1, median 6.6 months), all patients developed evident signs of facialmuscle weakness, even when ERT was started very early. When such weakness was first observed, its severity in most patients (9/11) was considered to be mild. The main characteristics were sunken cheeks (8/11) and a drooping lower lip (9/11). While the absence of the nasolabial fold and forehead lines were difficult to judge, four patients clearly had diminished nasolabial folds. Only one patient had ptosis.

The final photographs show that, despite ERT, facialmuscle weakness became severe in $7 / 11$ patients (Fig. 1). While the main features were still sunken cheeks $(10 / 11)$ and drooping of the lower lip (9/11), facial expression was clearly reduced by diminished nasolabial folds (7/11) and forehead lines (5/11). The number of patients with ptosis rose to four.

Speech and swallowing function

Speech

Speech was assessed in four patients at a median age of 4.1 years (age range 2.0-9.9 years, supplementary Table 2). Orofacial observation showed that the speech of all four was impaired by reduced movement and/or weakness of the lip and/or tongue. Their articulation was disordered,

Table 1 Patient characteristics and development of facial muscle weakness in 11 patients with classic infantile Pompe disease treated with ERT

\begin{tabular}{|c|c|c|c|c|c|c|c|c|c|}
\hline Patient & Gender & $\begin{array}{l}\text { Age at } \\
\text { diagnosis } \\
\text { (months) }\end{array}$ & $\begin{array}{l}\text { Age at the } \\
\text { start of ERT } \\
\text { (months) }\end{array}$ & $\begin{array}{l}\text { NGT at the } \\
\text { start of } \\
\text { ERT }\end{array}$ & $\begin{array}{l}\text { Age at } \\
\text { study end } \\
\text { (years) }\end{array}$ & $\begin{array}{l}\text { Invasive } \\
\text { ventilation** } \\
\text { (months) }\end{array}$ & $\begin{array}{l}\text { Maximal } \\
\text { motor } \\
\text { milestone }\end{array}$ & $\begin{array}{l}\text { Severity of first } \\
\text { observed FMW** } \\
\text { (months) }\end{array}$ & $\begin{array}{l}\text { Severity of FMW } \\
\text { on most recent } \\
\text { photo** (years) }^{*} \text {. }\end{array}$ \\
\hline 1 & M & 0.7 & 3.8 & $\mathrm{~N}$ & 11 & No & Walking & Mild (6.6) & Mild (11.6) \\
\hline 2 & $\mathrm{~F}$ & 3.6 & 7.2 & $\mathrm{Y}$ & 12 & $7 \dagger$ & Tetraplegic & Severe $(1.0 \ddagger)$ & Severe (11.4) \\
\hline 3 & $\mathrm{~F}$ & 0.6 & 3.0 & $\mathrm{Y}$ & $4 *$ & 26 & Sitting & Mild (5.5) & Severe (3.4) \\
\hline 4 & $\mathrm{~F}$ & 6.2 & 8.3 & $\mathrm{Y}$ & 12 & 11 & Tetraplegic & Mild (9.0) & Severe $(6.2 \S)$ \\
\hline 5 & M & 0.2 & 1.9 & $\mathrm{Y}$ & $4^{*}$ & 24 & Walking & Mild (13.8) & Severe (4.1) \\
\hline 6 & M & 0.7 & 1.2 & $\mathrm{Y}$ & 6 & No & Walking & Mild (3.4) & Severe (6.0) \\
\hline 7 & $\mathrm{~F}$ & 0.2 & 0.5 & $\mathrm{Y}$ & 5 & No & Walking & Mild (12.4) & Mild (5.5) \\
\hline 8 & $\mathrm{~F}$ & 3.2 & 3.6 & $\mathrm{Y}$ & $0.8^{*}$ & No & Minimal movements & Mild $(6.9 \S)$ & Mild $(0.6 \S)$ \\
\hline 9 & M & 0.1 & 0.1 & $\mathrm{Y}$ & 3 & 33 & Walking & Mild (15.0) & Severe (3.0) \\
\hline 10 & M & 2.0 & 2.2 & $\mathrm{~N}$ & 3 & No & Sitting & Severe (2.0) & Severe (2.7) \\
\hline 11 & $\mathrm{~F}$ & 2.3 & 2.4 & $\mathrm{~N}$ & 2 & No & Walking & Mild (2.3) & Mild (1.7§) \\
\hline
\end{tabular}

$\mathrm{F}=$ Female, $\mathrm{M}=$ Male, $\mathrm{NGT}=$ Nasogastric tube feeding, $\mathrm{Y}=$ Yes, $\mathrm{N}=\mathrm{No}, *=$ Died, $* *=$ Age in months or years, $\dagger=$ Invasive ventilation before start of ERT, FMW=Facial muscle weakness, $\$=$ Photographs were available before start of ERT, $\S=$ last available picture due to referral to treatment abroad (4), early death (8), and short treatment duration at the end of this study (11) 

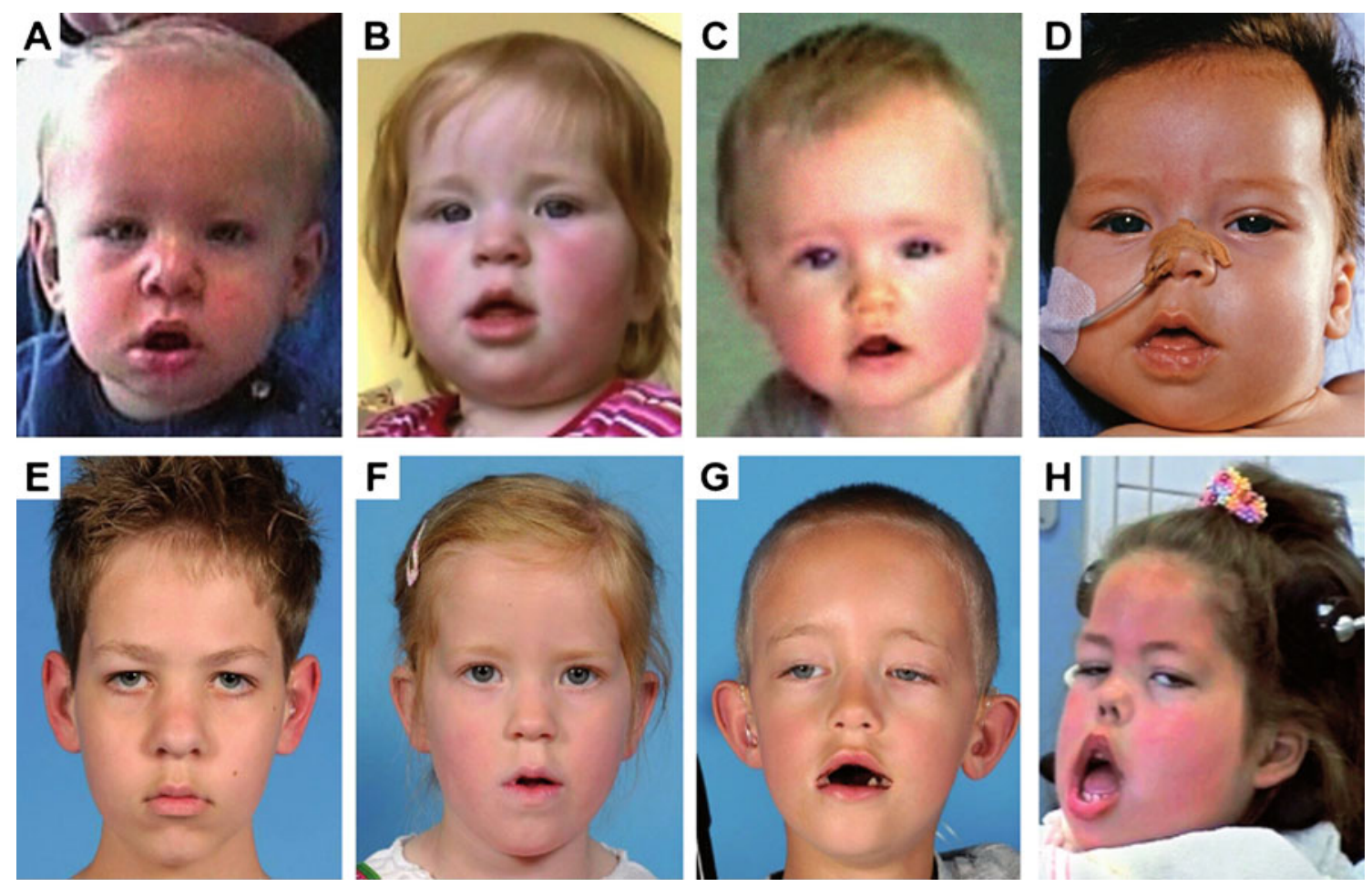

Fig. 1 Development of facial muscle weakness over time in four patients with classic infantile Pompe disease treated with ERT. Per patient, comparison of the first photograph which showed the first signs of facialmuscle weakness (a-d) with the most recent photograph (e-h) showed

that facial muscle weakness remained mild in two patients (a and $\mathbf{b}$ compared to $\mathbf{e}$ and $\mathbf{f}$ ), but became severe in one patient (c compared to g). One patient presented with severe facial muscle weakness at the age of 1 month; this persisted over time (d compared to $\mathbf{h}$ )

featuring consonant substitutions, consonant omissions and cluster reductions, mild to moderate hypernasal resonance, and significantly impaired speech intelligibility. Together, this suggested velopharyngeal incompetence.

Three patients were reassessed at a median age of 5.5 years (age range 5.1-11.1 years). In the period between the first and second assessment, no major changes in orofacial hypotonia or speech were observed, although speech therapy had improved the active articulatory compensation. Additional investigation of dysarthria in these three patients showed disorders in respiration, phonation and prosody. They spoke in short sentences in a monotone, hoarse wet voice with monoloudness. These features are specific for flaccid dysarthria.

\section{Swallowing function}

Swallowing function was assessed in six patients at a median age of 3.0 years (age range 8.0 months to 9.9 years). Feeding difficulties were reported (5/6), and comprised all parameters (see supplementary Table 2). Patient 9 was fed completely by nasogastric tube, and ingested only water orally. Observation of mastication revealed impaired mastication in two patients.

Fibreoptic endoscopic examinations of swallowing showed that five of the six patients had varying extents of dysphagia; only the youngest had no swallowing abnor- malities. Reduced velopharyngeal closure was found in four patients, and caused nasal regurgitation in two. Although the anatomy of the swallowing apparatus and function of the larynx were normal, pharyngeal muscle contraction was reduced $(5 / 6)$. This resulted in pooling secretions in the pharynx (4/6), which, in two patients, contained remnants of a previous meal (Fig. 2a).

Swallowing of various textures of food could be examined in four patients, whereas swallowing function of two patients who refused to eat during the examination ( 9 and 10) was evaluated on the basis of dry swallows. In all patients with insufficient muscle contraction of the pharynx $(5 / 6)$, residues of food or saliva remained present at the valleculae, pharyngeal wall, pyriform sinuses and postcricoid. Because patients used no protective reflexes such as coughing or swallowing to try to clear the food, it was clear that the sensory reaction of the pharynx was impaired $(2 / 6)$. In three patients, pharyngeal residues resulted in penetration of food or saliva (Fig. 2b). In two of the six patients, the sensory reaction of the larynx was impaired.

Swallowing function was reassessed in four patients, at a median age of 5.3 years (age range 2.0-11.1 years). In three patients it remained stable; in the other (Patient 7), it deteriorated, leading to aspiration, premature spillage of food, and delayed onset of swallowing. 
Fig. 2 FEES examination in a 6-year old boy with classic infantile Pompe disease treated with ERT. Pooled secretions in the pharynx containing saliva and remnants of previously eaten food at FEES examination (a), and pharyngeal food residue with penetration and aspiration directly after food intake (b)
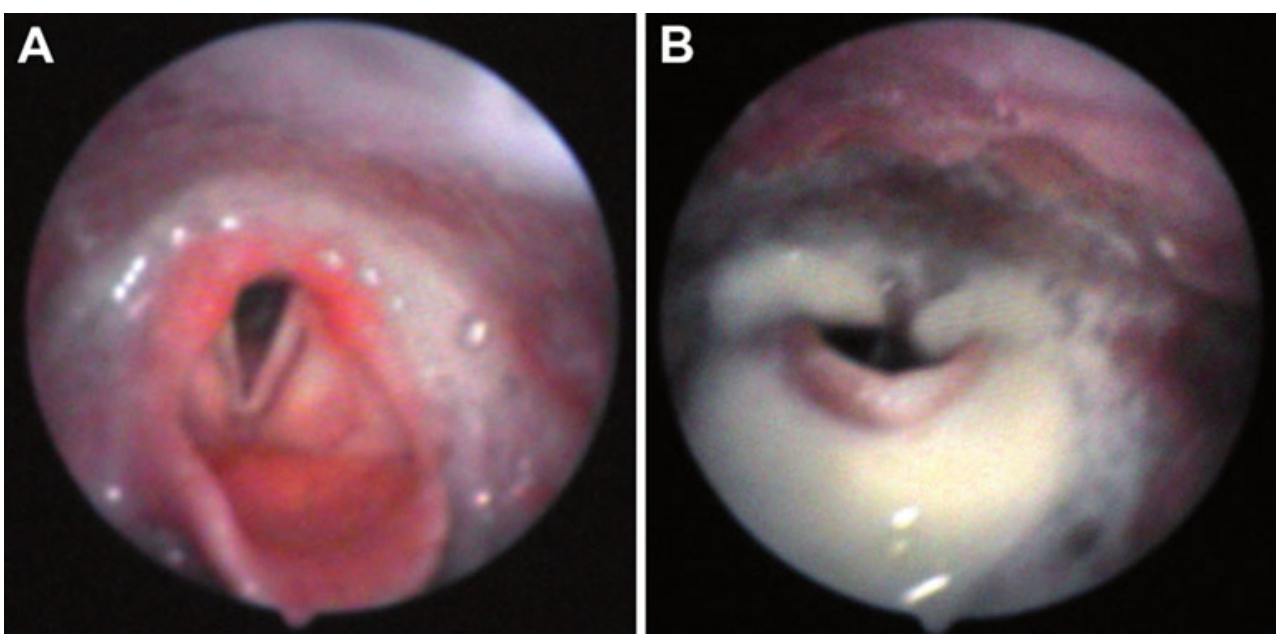

\section{Associated clinical outcome measures}

At the start of ERT, feeding through a nasogastric tube (NGT) was required by eight of the 11 patients. By the end of the study, five patients were completely orally fed. Their ages were 2, 3, 6, 6, and 11 years. Two patients have never required NGT feeding since ERT began.

Hearing was impaired in all patients except Patient 9, their hearing deficits ranging from 30-90 dB (Van Capelle et al. 2010). Three of the four patients whose speech was evaluated already had hearing aids at first evaluation. The other patient (7) needed hearing aids later; he had a mild hearing loss of $30-40 \mathrm{~dB}$.

Five of the six patients whose swallowing function was assessed, learned to walk (see Table 1 and supplementary Table 2 for motor outcome), and three of the same six patients had recurrent respiratory infections.

\section{Discussion}

The longest survivors receiving enzyme-replacement therapy for infantile Pompe disease are currently 12 years old. It is evident not only that ERT has significantly increased survival, but also that it greatly affects these children's motor performance. However, this longer survival has also highlighted previously unrecognized aspects of the disease. Noting that many children had developed facial-muscle weakness over time, we investigated the frequency and consequences of facial-muscle weakness, speech disorders and dysphagia in long-term survivors.

In all 11 patients, facial-muscle weakness had developed before the age of 15 months. When first observed, its main features were poor facial expression, sunken cheeks and drooping of the lip. Over the years, all facial muscles seemed to become affected. FEES examinations showed weakness of the bulbar muscles, with velopharyngeal incompetence and reduced muscular contraction of the pharynx.

This muscle weakness affected daily functioning in four main ways. 1.) All patients had poor facial expression. 2.) Four children developed a bilateral ptosis over time, which was so severe in one child that surgical correction was required (Slingerland et al. 2011). 3.) Speech was abnormal, characterized by disordered articulation, hypernasality, and lower intelligibility - all typical of velopharyngeal incompetence (Darley et al. 1969a), as suggested earlier by Muller et al. (Muller et al. 2009). 4.) Swallowing was generally weak and ineffective, leaving residues of food around the larynx, with penetration in three out of six patients. As some patients lack protective sensory reactions of the pharynx and larynx, aspirations and micro-aspirations may easily occur and go unnoticed. In retrospect, we suspect that this phenomenon explains the recurrent airway infections in three patients in our study. As respiratory muscle weakness can easily lead to respiratory insufficiency, such aspirations and aspiration pneumonias may be life threatening. As it has proved difficult to wean patients with classic infantile Pompe off the ventilator, this is particularly important. Earlier studies have shown that, despite treatment with ERT, $50 \%$ of classic infantile patients eventually become ventilator dependent, and that respiratory insufficiency is the main cause of death (Kishnani et al. 2009).

We found no clear relationship between the age at start of ERT and the point at which facial-muscle weakness developed, although the severest facial muscle weakness was found in patients who started ERT late - at 7 and 8 months of age. ERT seemed to reduce feeding difficulties in some patients. During enzyme therapy, nasogastric tube feeding could be discontinued in three of eight patients who needed NGT at start. At the end of the study, five patients in age ranges from 2-12 years were completely orally fed. Still, four of these patients showed some signs of dysphagia. It is noteworthy that the patients who were fed orally were the best performers. Four of these five patients 
learned to walk and were still walking at the end of the study. ERT could not prevent disordered speech, although the severest speech problems were observed in those with the poorest motor outcome.

Our study indicated that parents often underreport signs of choking and swallowing difficulties. Given the findings of our study, we attach paramount importance to assessments of swallowing function especially in young patients. To prevent aspiration and pneumonia, it may be advisable to modify dietary texture, or even to discontinue oral feeding in high-risk patients. A low maintenance dose of antibiotics may also be helpful. To improve speech, feeding and swallowing difficulties as much as possible, we recommend early examination and treatment by a speech therapist. In patients with severe hypernasal resonance, however, only slight gains on speech can be achieved by behavioural exercises. Other options to improve speech include a palatal lift prothesis, or surgical interventions such as pharyngoplasty or a pharyngeal flap (Rudnick and Sie 2008). But as these may also increase swallowing difficulties or cause obstructive sleep apnoea, they should be used with caution. Their overall effect may also be limited by the residual pharyngeal muscle weakness that remains in patients with classic infantile Pompe disease.

Hearing loss is common in classic infantile Pompe patients, and may also impact speech development. We earlier recommended regular auditory tests, and early implementation of hearing aids (Van Capelle et al. 2010).

The exact cause of bulbar muscle weakness is unknown. In infants with Pompe disease, it has been shown that glycogen accumulates in the tongue of an untreated infant (Sakurai et al. 1974), but the effect of ERT on bulbar muscle pathology in these infants has not been studied. Only one case report addresses the effect of ERT on bulbar muscle pathology in an adult patient with Pompe disease and showed that, 21 months after treatment with ERT, residual storage of glycogen remained in the oesophagus (Kobayashi et al. 2010). This is in line with results obtained in Pompe knock-out mice, which showed that extensive glycogen storage present in bulbar muscles was not completely cleared by ERT (Bijvoet et al. 1999).

Together, these findings suggest that residual muscle pathology of the bulbar muscles almost certainly plays a major role in the speech and swallowing problems described in this study. It cannot be excluded that a role is also played by glycogen storage in the nervous system. Autopsies of untreated patients with classic infantile Pompe disease have shown glycogen accumulation in the glial cells of the cortex, thalamus, brainstem, and spinal anterior motor horns (Gambetti et al. 1971; Mancall et al. 1965; Martin et al. 1973). Since ERT cannot cross the blood-brain barrier, ERT is unlikely to affect the glycogen storage in the central nervous system (Begley et al. 2008).
Certain features of the speech of the children in our study may reflect flaccid dysarthria (Darley et al. 1969b, a), a condition caused by damage to the lower motor neurons emerging from the brainstem. The lower sensibility of the larynx and pharynx and the delayed swallowing seen in some patients might also indicate involvement of the nervous system. Further research is required.

All in all, we could not fully explain why obvious bulbar muscle weakness developed even in good responders to ERT with a good motor outcome. If muscle pathology indeed underlies the clinical problems, this may imply that bulbar muscles respond less to ERT than the muscles of the limbs and trunk.

Several studies have sought to explain the differential response of muscles to ERT. One potential explanation involved variation in response by different muscle-fibre types. It was shown in mice with Pompe disease that type 2 muscle fibres were largely resistant to ERT (Raben et al. 2005). In humans, type 1 and type $2 \mathrm{a}$ muscle fibres both responded to enzyme therapy (Drost et al. 2008). Comparison of skeletal muscles from the limb and trunk with bulbar muscles shows that bulbar muscles have a wider repertoire of contractile proteins, including developmental and specialized isoforms of myosin and hybrid fibers that express two or more isoforms (Hoh 2005; Kent 2004; Sciote et al. 2003). This might contribute to a lower response to ERT in these muscles. While the results of our studies in knock-out mice with Pompe disease have not confirmed a smaller response of the bulbar muscles, the situation might be different in humans (Bijvoet et al. 1999).

In conclusion, we have shown that facial-muscle weakness, speech disorders and dysphagia are prominent in patients with classic infantile Pompe disease who survive due to enzyme therapy. Bulbar muscle weakness caused speech disorders, severely reducing speech intelligibility, thereby affecting communication and social interaction. Early treatment by a speech therapist might help to improve articulation and speech. Similarly, because ineffective swallowing puts patients at risk for the development of aspiration pneumonias and respiratory insufficiency, early and regular swallowing assessments and development of a safe feeding plan are recommended. Further research is necessary to elucidate the exact pathophysiology.

Acknowledgements We would like to thank the patients and the parents for participating in the study, David Alexander for his critical reading of the manuscript and Tom de Vries Lentsch for layout of the graphs.

Conflict of interest and sources of funding The Research on Pompe disease at Erasmus MC was financially supported by the Erasmus MC Revolving Fund (NAMEvdB, project no 1054), ZonMw -Dutch organization for healthcare research and innovation of care [Grant 152001005], The 'Prinses Beatrix Fonds (project number OP07-08)'. 
ATvdP participates in the 7th Frame Program "EUCLYD-a European Consortium for Lysosomal Storage Diseases" of the European Union (health F2/2008 grant agreement 201678) including diagnostic research in the field of Pompe disease. As of August 2004, ATvdP provides consulting services for Genzyme Corp, Cambridge, MA, USA, under an agreement between Genzyme Corp and Erasmus MC, Rotterdam, the Netherlands. This agreement also caters to financial support for Erasmus MC for research in Pompe's disease. Erasmus MC and inventors for the method of treatment of Pompe's disease by enzyme replacement therapy receive royalty payments pursuant to Erasmus MC policy on inventions, patents and technology transfer.

Open Access This article is distributed under the terms of the Creative Commons Attribution Noncommercial License which permits any noncommercial use, distribution, and reproduction in any medium, provided the original author(s) and source are credited.

\section{References}

Amalfitano A, Bengur AR, Morse RP et al. (2001) Recombinant human acid alpha-glucosidase enzyme therapy for infantile glycogen storage disease type II: results of a phase I/II clinical trial. Genet Med 3:132-138

Begley DJ, Pontikis CC, Scarpa M (2008) Lysosomal storage diseases and the blood-brain barrier. Curr Pharm Des 14:1566-1580

Bijvoet AG, Van Hirtum H, Kroos MA et al. (1999) Human acid alphaglucosidase from rabbit milk has therapeutic effect in mice with glycogen storage disease type II. Hum Mol Genet 8:2145-2153

Chakrapani A, Vellodi A, Robinson P, Jones S, Wraith JE (2010) Treatment of infantile Pompe disease with alglucosidase alpha: the UK experience. J Inherit Metab Dis 33:747-750

Darley FL, Aronson AE, Brown JR (1969a) Clusters of deviant speech dimensions in the dysarthrias. J Speech Hear Res 12:462-496

Darley FL, Aronson AE, Brown JR (1969b) Differential diagnostic patterns of dysarthria. J Speech Hear Res 12:246-269

Drost MR, Schaart G, van Dijk P et al. (2008) Both type 1 and type 2a muscle fibers can respond to enzyme therapy in Pompe disease. Muscle Nerve 37:251-255

Dubowitz V (1978) Muscle Disorders in Childhood. Sauders, London and Philadelphia

Gambetti P, DiMauro S, Baker L (1971) Nervous system in Pompe's disease. Ultrastructure and biochemistry. J Neuropathol Exp Neurol 30:412-430

Hirschhorn R, Reuser AJJ (2001) Glycogen storage disease type II: acid alpha-glucosidase (acid maltase) deficiency. In: Scriver CR, Beaudet AL, Valle D, Sly WS (eds) The metabolic and molecular bases of inherited disease. McGraw-Hill, New York, pp 3389-3420

Hoh JF (2005) Laryngeal muscle fibre types. Acta Physiol Scand 183:133-149

Kent RD (2004) The uniqueness of speech among motor systems. Clin Linguist Phon 18:495-505

Kishnani PS, Hwu WL, Mandel H, Nicolino M, Yong F, Corzo D, Infantile-Onset Pompe Disease Natural History Study Group (2006a) A retrospective, multinational, multicenter study on the natural history of infantile-onset Pompe disease. J Pediatr 148:671-676

Kishnani PS, Nicolino M, Voit T et al. (2006b) Chinese hamster ovary cell-derived recombinant human acid alpha-glucosidase in infantile-onset Pompe disease. J Pediatr 149:89-97

Kishnani PS, Corzo D, Nicolino M et al. (2007) Recombinant human acid [alpha]-glucosidase: major clinical benefits in infantile-onset Pompe disease. Neurology 68:99-109
Kishnani PS, Corzo D, Leslie ND et al. (2009) Early treatment with alglucosidase alfa prolongs long term survival of infants with Pompe disease. Pediatr Res 66:329-335

Klinge L, Straub V, Neudorf U et al. (2005a) Safety and efficacy of recombinant acid alpha-glucosidase (rhGAA) in patients with classical infantile Pompe disease: results of a phase II clinical trial. Neuromuscul Disord 15:24-31

Klinge L, Straub V, Neudorf U, Voit T (2005b) Enzyme replacement therapy in classical infantile pompe disease: results of a tenmonth follow-up study. Neuropediatrics 36:6-11

Kobayashi H, Shimada Y, Ikegami M et al. (2010) Prognostic factors for the late onset Pompe disease with enzyme replacement therapy: from our experience of 4 cases including an autopsy case. Mol Genet Metab 100:14-19

Langmore SE (2001) Endoscopic Evaluation and Treatment of Swallowing Disorders. Thieme Medical Publishers, New York

Langmore SE, Schatz K, Olsen N (1988) Fiberoptic endoscopic examination of swallowing safety: a new procedure. Dysphagia 2:216-219

Mancall EL, Aponte GE, Berry RG (1965) Pompe's Disease (Diffuse Glycogenosis) with Neuronal Storage. J Neuropathol Exp Neurol 24:85-96

Martin JJ, de Barsy T, van Hoof F, Palladini G (1973) Pompe's disease: an inborn lysosomal disorder with storage of glycogen. A study of brain and striated muscle. Acta Neuropathol 23:229 244

Muller CW, Jones HN, O'Grady G, Suarez AH, Heller JH, Kishnani PS (2009) Language and speech function in children with infantile Pompe disease. J Pediatr Neurol 7:147-156

Nicolino M, Byrne B, Wraith JE et al. (2009) Clinical outcomes after long-term treatment with alglucosidase alfa in infants and children with advanced Pompe disease. Genet Med 11:210-219

Pompe JC (1932) Over Idiopathische Hypertrofie van het Hart. Ned Tijdschr Geneeskd 76:304-311

Raben N, Fukuda T, Gilbert AL et al. (2005) Replacing acid alphaglucosidase in Pompe disease: recombinant and transgenic enzymes are equipotent, but neither completely clears glycogen from type II muscle fibers. Mol Ther 11:48-56

Rudnick EF, Sie KC (2008) Velopharyngeal insufficiency: current concepts in diagnosis and management. Curr Opin Otolaryngol Head Neck Surg 16:530-535

Sakurai I, Tosaka A, Mori Y, Imura S, Aoki K (1974) Glycogenosis type II (Pompe). The fourth autopsy case in Japan. Acta Pathol Jpn 24:829-846

Sciote JJ, Horton MJ, Rowlerson AM, Link J (2003) Specialized cranial muscles: how different are they from limb and abdominal muscles? Cells Tissues Organs 174:73-86

Slingerland NW, Polling JR, van Gelder CM, van der Ploeg AT, Bleyen I (2011) Ptosis, extraocular motility disorder, and myopia as features of pompe disease. Orbit 30:111-113

Van Capelle CI, Goedegebure A, Homans NC, Hoeve HL, Reuser AJ, van der Ploeg AT (2010) Hearing loss in Pompe disease revisited: results from a study of 24 children. J Inherit Metab Dis 33:597602

Van den Hout H, Reuser AJ, Vulto AG, Loonen MC, Cromme-Dijkhuis A, Van der Ploeg AT (2000) Recombinant human alpha-glucosidase from rabbit milk in Pompe patients. Lancet 356:397-398

Van den Hout HM, Hop W, van Diggelen OP et al. (2003) The natural course of infantile Pompe's disease: 20 original cases compared with 133 cases from the literature. Pediatrics $112: 332-340$

Van den Hout JM, Kamphoven JH, Winkel LP et al. (2004) Long-term intravenous treatment of Pompe disease with recombinant human alpha-glucosidase from milk. Pediatrics 113:e448-e457

Van der Ploeg AT, Reuser AJ (2008) Pompe's disease. Lancet 372:1342-1353 